\title{
Treatment of Ulnar Impaction Syndrome A Systematic Review
}

M.G.El-D.Alashhab, O.M.Essawy, E.A.Tabl and A.S.Elshahat

Orthopedic Surgery Dept., Faculty of Medicine, Benha Univ., Benha, Egypt

E-Mail:A.Elshahat@gmail.com

\begin{abstract}
This thesis critically and systematically reviews the surgical treatments for ulnar impaction syndrome. Three types of treatments currently exist: arthroscopic wafer procedure, open wafer procedure, and ulna shortening osteotomy. We aim in this study to systematically review the literature to assess the treatment of the ulnar impaction syndrome which will help in establishing an algorithm for the treatment. By September 2018, we conducted a search on five electronic databases, including PubMed, Scopus, Institute of Science Index (ISI), Google Scholar and Cochrane. We used the following search terms to retrieve the articles that may relate to our topic: (ulnar abutment syndrome, ulnar impaction syndrome) A total of 36 articles were included from searching the electronic databases PubMed MEDLINE, Ovid MEDLINE, and Ovid EMBASE. Studies were evaluated for quality using the Modified Detsky Score. Of these, 14 articles had a Modified Detsky Score of 6/10 or higher. Satisfaction rates were 100\% for arthroscopic wafer procedure, $89 \%$ for open wafer procedure, and $84 \%$ for ulna shortening osteotomy. The percentage of participants reporting an excellent or good outcome was $82 \%$ for arthroscopic wafer procedure, $87 \%$ for open wafer procedure, and $76 \%$ for ulna shortening osteotomy. Available evidence shows that arthroscopic wafer procedure and open wafer procedure may be viable alternatives to the more popular ulna shortening osteotomy, but clinical superiority is yet to be established. Future research should focus on prospective cohort methods and should report participant outcomes using validated scoring methods.
\end{abstract}

Keywords: Wafer procedure, Outcome, Modified Detsky Score, Ulnar impaction syndrome.

\section{Introduction}

Ulna impaction syndrome (UIS) might have been primary introduced Toward milch On 1941, which might have been guided toward those wrist ulna agreed agony brought on by Colles fracture-induced spiral shortening Furthermore wrist ulna impaction prompted lunate corruption. It is discovered Toward Scrutinize and clinical experience that the wrist trauma is not those main danger component from claiming UIS. Different elements for example, unending wrist weariness and occupation malady might likewise reason UIS [1]. Otherwise called ulna abutment syndrome or ulnocarpal abutment syndrome, may be described Eventually Tom's perusing frightful layering between the distal osteochondral surface of the ulmus thomasii and the proximal lunate Also triquetrum. An dominant part for patients with ulna impaction syndrome bring ulna certain difference. This might a chance to be static, seen around neutral-rotation posteroanterior (pa) radiographs of the wrist, alternately dynamic, made by pronation of the lower arm or compelling gripping. Both degenerative (palmer 2c, 2d, and 2e classifications) Furthermore traumatic (palmer 1a classification) lesions of the triangular fibrocartilage perplexing (tfcc) are normally seen with ulna impaction syndrome. Done patients with ulna impaction side effects who need aid ulna positive, diminishing load-sharing through those ulna carpus Toward ulna subsidence will be necessary on mitigate manifestations [2]. Those pathogenesis is basically the wrist ulna overload, which reasons unending effect for ulna head, triangular fibrocartilage complex (TFCC) and lunate What's more triangular bone. This prompts sustenance issue of the blood supply What's more synovial liquid for ulna wrist structure, bringing about ulna wrist joint degeneration. Ultimately, an aggregation about syndrome for example, such that ulna wrist agony and utilitarian constraint happen. For the advancement for handiwork industry Also expansion of Different meets expectations that have an expansive add up for rehashed wrist ulna deviation strength, the frequency for UIS is increasing, yet the customary basic ulna shortening osteotomy need a greater amount difficulties [2]. The ulna side of the wrist comprises about a few significant anatolian dialect structures that help soundness yet consider progressive movement and the capacity should produce a capable grip through ulna deviation. Those innate ligaments comprise of the capitohamate ligament and the lunotriquetral ligament.

These ligaments go about as stabilizers between those distal ulmus thomasii Furthermore volar carpus. These ligament fibers begin from the volar perspective of the triangular fibrocartilage complex (tfcc) with a commitment from those ulna styloid. They embed under the volar portions of the lunate, triquetrum, Furthermore lunotriquetral ligament [3]. Those ulna nonpartisan wrist, $80 \%$ of the load will be exchanged over those radiocarpal joint Concerning illustration compared for $20 \%$ over those ulnocarpal joint. The point when difference increments from unbiased on 2.5 $\mathrm{cm}$ positive, however, ulnocarpal load expands Toward roughly $20 \%$. Expanding ulna period brings about an build in power transmission crosswise over the distal ulna, and it will be referred to that lower arm pronation Furthermore Commanding grip build ulna difference [4].

\section{Methodology}

Five electronic databases were used to find relevant studies published in English.

\subsection{Search Strategy}

By September 2018, we conducted a search on five electronic databases, including PubMed, Scopus, Institute of Science Index (ISI), Google Scholar and Cochrane. We used the following search terms to 
retrieve the articles that may relate to our topic: (ulnar abutment syndrome, ulnar impaction syndrome).

\subsection{Statistical methods}

Statistical analyses Review Manager (RevMan 5.3) software was used to analyze the data. Individual and pooled incidences were calculated for the included studies with $95 \%$ CI. For studies without heterogeneity, a fixed model was used, while for studies with heterogeneity, a random model was used. Statistical heterogeneity was evaluated using the chi-square test and if I 2 was greater than $20 \%$, the random model was used. The RR with $95 \%$ CI was calculated for dichotomous data, while mean differences (MDs) were calculated for continuous data. A p value $<0.05$ was considered significant.

\subsection{Inclusions criteria}

Study that gives information regarding ulnar impaction syndrome, no restriction as regard age of the patient, the study design or year of research, the population was composed of patients having surgery for symptomatic, the surgical intervention was either ulnar shortening osteotomy, OWP, or AWP, the study included either a subjective or an objective outcome measure and study published in English only.

\subsection{Exclusion criteria}

Studies not related to ulnar impaction syndrome, studies discussed uncommon procedures and non English.

\section{Results}

A total of 36 articles were included in final analysis, 14 of which were deemed high quality Table (1).

In study was conducted as a retrospective study of 18 patients presenting with ulnar impaction syndrome of various aetiologies, with an average follow-up of 5.9 \pm 3.4 years. Seventeen patients $(94.4 \%)$ were satisfied and would undergo the operation again. Although most patients reported residual complaints $(83.3 \%)$ such as weakness $(38 \%)$ or pain under given specific circumstances, objective measurements of wrist function were good. The average Mayo Wrist Score was $75.9 \pm 13.4(\mathrm{n}=16)$ and the average DASH score was $18.0 \pm 13(n=12)$. Comparison of the operated and healthy limb did not show any significant difference in strength or range of motion, except for significantly reduced flexion on the operated side $(\mathrm{p}<0.05)$. In this study, ulna-shortening osteotomy provided a good functional outcome and high subjective satisfaction over the long term. Table (2)

In study. They asked whether preoperative factors influenced the postoperative score of ulnar shortening osteotomy combined with arthro-scopic débridement of the triangular fibrocartilage complex. We retrospectively reviewed 51 patients (53 wrists) with ulnar impaction syndrome treated with this procedure. There were 28 males and 23 females ranging in age from 14 to 67 years (mean, 37.5 years). The minimum followup was 12 months (mean, 26.3 months; range,
12-95 months). At last followup, we determined a modified Mayo wrist score for each patient. Preoperative factors affecting the clinical score were identified using multiple regression analysis. The clinical score ranged from 40 to 100 points (mean, 84.5 points). A long duration of symptoms and workers' compensation pre-dicted worse clinical scores. They recommend considering these two factors when deciding whether to perform this procedure. Table (3).

Many of the subjective rating scales employed by UIS studies give a numerical score that is translated to a rating of excellent, good, fair, or poor Fig (1). Two AWP studies had an average of $81.8 \%$ excellent or good outcome. Three OWP studies had an average of $87.1 \%$ excellent or good outcome. Fourteen USO studies had an average of $75.7 \%$ excellent or good outcome.

\section{Discussion}

UIS may be synonymous for ulno-carpal impaction syndrome Also ulno-carpal abutment, Be that as is a dissimilar substance starting with ulna styloid impaction What's more ulna impingement syndrome. Ulna styloid impaction will be brought on Eventually Tom's perusing impaction the middle of the ulna styloid and the proximal triquetrum; ulna impingement syndrome is characterized Eventually Tom's perusing An abbreviated ulmus thomasii impinging on the distal span [5]. UIS might prompt degen-erative lesions of the triquetrum, lunate, ulna mind cartilage, or of the TFCC. Concomitantly those triquetro-lunate ligaments might make disturbed. Copartnered elements from claiming ulno-carpal joint space narrowing might incorporate past crack (e. G. Of the distal radius), premature physeal capture of the distal radius, alternately intrinsic ulmus thomasii sure difference Table $(4,5)$.

Medication is at first non-operative. In nonoperative administration fails, surgery on decompress those ulno-carpal joint will be shown. Joint decompression might make attained Toward whichever ulmus thomasii shortening osteotomy (USO) or Toward wafer system. Wafer pro-cedure might make Possibly arthroscopic (AWP) alternately open (OWP). Different strategies to performing USO have been portrayed .

Those decision for surgical medication for recalcitrant UIS is generally In light of specialist Inclination offers Inclination. Every surgery need interesting risks, however there exists no high-keyed proof with brief choice making .

This article critically Also deliberately reviews those systems utilized should ponder the surgical medicines to UIS. The place possible, effects of homogeneous investigations need aid pooled and conclusions correlations need aid made with elucidate the current state about ulno -carpal decompressive methods Also on aide future research .

The foundation of medication about ulna impaction will be mechanical decompression of the ulnocarpal explanation Toward diminishing ulna difference. Shortening of the ulmus thomasii or resection of the distal ulmus thomasii fundamentally abatements 
strengths crosswise over the ulna wrist [6]. Different surgical methods need been recommended to treat this ulna impaction syndrome. They are all In view of decom-pression of the ulnocarpal joint. Biomechanical investigations of palmer et al have demonstrated that $18 \%$ of the stacking weight crosswise over those wrist may be borne Toward those ulnocarpal explanation Also that, Toward shortening the ulmus thomasii 2. 5 $\mathrm{mm}$, this stacking weight may be diminished to $4.3 \%$. [7]. Those ulna shortening osteotomy is an extraarticular procedure Furthermore need those hypothetical focal point from claiming keeping up those distal radioulnar joint (DRUJ) and the fringe part of the triangular fibrocartilage intricate (TFCC) [8]. Those conclusions for ulna shortening osteotomy, de-scribed in the literature, were beneficial alternately phenomenal in the lion's share of the instances. The wafer resection of the distal ulmus thomasii Additionally abatements those weight on the ulnocarpal joint [9]. Best constrained amount from claiming open situations need been accounted. With the advancement about arthroscopic resection techniques, another enthusiasm toward this technobabble risen. Over our patients, however, those effects of ulna shortening were not Likewise sure [10]. The general Conclusion might have been not that good, What's more ulna shortening osteotomy didn't dependably appear to be should a chance to be those ultimacy great methodology for ulna abutment. Difficulties were technique interfaced What's more not identified with an inadequate finding about ulna wrist ache Table (6), Fig (1) .

Table (1) High quality studies included in review.

\begin{tabular}{|c|c|c|c|c|c|c|c|c|}
\hline Study & Treatment & $\begin{array}{l}\text { Quality } \\
\text { Score* }\end{array}$ & Year & Country & Journal & Design & $\mathbf{N}$ & $\begin{array}{l}\text { Level of } \\
\text { Evidence }\end{array}$ \\
\hline $\begin{array}{l}\text { Tomaino and } \\
\text { Weiser }\end{array}$ & AWP & $6 / 10$ & 2001 & USA & J Hand Surg (Am) & $\begin{array}{l}\text { Retrospective case } \\
\text { series }\end{array}$ & 12 & IV \\
\hline Berstein et al. & $\begin{array}{l}\text { AWP vs } \\
\text { USO }\end{array}$ & $7 / 10$ & 2004 & USA & Arthroscopy & $\begin{array}{l}\text { Retrospective cohort } \\
\text { study }\end{array}$ & 27 & III \\
\hline Tomaino & OWP & $6 / 10$ & 1999 & USA & J Hand Surg (Br) & $\begin{array}{l}\text { Retrospective case } \\
\text { series }\end{array}$ & 13 & IV \\
\hline $\begin{array}{l}\text { Tomaino and } \\
\text { Shah }\end{array}$ & OWP & $6 / 10$ & 2001 & USA & Am J Orth & $\begin{array}{l}\text { Retrospective case } \\
\text { series }\end{array}$ & 26 & IV \\
\hline $\begin{array}{l}\text { Constantine } \\
\text { et al. }\end{array}$ & $\begin{array}{l}\text { OWP vs } \\
\text { USO }\end{array}$ & $7 / 10$ & 2000 & USA & J Hand Surg (Am) & $\begin{array}{l}\text { Retrospective cohort } \\
\text { study }\end{array}$ & 22 & III \\
\hline $\begin{array}{l}\text { Moermans et } \\
\text { al. }\end{array}$ & USO & $6 / 10$ & 2007 & Belgium & $\begin{array}{l}\text { Scand J Plast } \\
\text { Reconstr Surg } \\
\text { Hand Surg }\end{array}$ & $\begin{array}{l}\text { Retrosp series ective } \\
\text { case }\end{array}$ & 28 & IV \\
\hline Nunez et al. & USO & $6 / 10$ & 2012 & USA & J Hand Surg (Am) & $\begin{array}{l}\text { Prospective case } \\
\text { series }\end{array}$ & 6 & IV \\
\hline Baek et al. & USO & $6 / 10$ & 2011 & $\begin{array}{l}\text { South } \\
\text { Korea }\end{array}$ & Clin Orthop Surg & $\begin{array}{c}\text { Retrospective case } \\
\text { series }\end{array}$ & 36 & IV \\
\hline $\begin{array}{l}\text { Kitzinger et } \\
\text { al. }\end{array}$ & USO & $6 / 10$ & 2007 & Germany & Ann Plast Surg & $\begin{array}{l}\text { Retrospective case } \\
\text { series }\end{array}$ & 27 & IV \\
\hline Kim and Song & USO & $7 / 10$ & 2011 & South & Clin Orthop Surg & $\begin{array}{l}\text { Retrospective cohort } \\
\text { study }\end{array}$ & 19 & III \\
\hline Luria et al. & USO & $7 / 10$ & 2008 & USA & J Hand Surg (Am) & $\begin{array}{l}\text { Retrospective case } \\
\text { series }\end{array}$ & 54 & IV \\
\hline Cherchel et al. & USO & $7 / 10$ & 2012 & Belgium & Acta Orthop Belg & $\begin{array}{c}\text { Retrospective case } \\
\text { series }\end{array}$ & 18 & IV \\
\hline Baek et al. & USO & $8 / 10$ & 2005 & $\begin{array}{l}\text { South } \\
\text { Korea }\end{array}$ & $\begin{array}{l}\text { J Bone Joint Surg } \\
\text { (Am) }\end{array}$ & $\begin{array}{l}\text { Retrospective case } \\
\text { series }\end{array}$ & 31 & IV \\
\hline Iwasaki et al. & USO & $8 / 10$ & 2007 & Japan & $\begin{array}{l}\text { Clin Orthop Relat } \\
\text { Res }\end{array}$ & $\begin{array}{l}\text { Retrospective case } \\
\text { series }\end{array}$ & 53 & IV \\
\hline
\end{tabular}

Table (2) Types of complaints reported by patients. Cherchel et al. (2012)

\begin{tabular}{llc}
\hline \multicolumn{1}{c}{ Complaint } & N & \% $(\mathbf{n}=\mathbf{1 8})$ \\
\hline Weakness & 7 & 38.9 \\
Pain (unspecified) & 4 & 22.2 \\
Pain upon leaning on hand & 4 & 22.2 \\
Stiffness & 4 & 22.2 \\
Decreased range of motion & 4 & 22.2 \\
Barometric pressure pain & 3 & 16.7 \\
Pain during specific activity & 2 & 11.1 \\
Scar pain & 2 & 11.1 \\
Swelling & 2 & 11.1 \\
«Popping» & 2 & 11.1 \\
\hline
\end{tabular}


Table (3) Comparison of strengthand wristrange of motion between the operated limb and the healthy limb .

\begin{tabular}{lccc}
\hline \multicolumn{1}{c}{ Parameter } & Operated limb & Healthy limb & Difference \\
\cline { 2 - 4 } & (average) & (average) & NS \\
\hline Grip strength (kg) & $31.4 \pm 13.2$ & $35.1 \pm 16.0$ & $p<0.05$ \\
Flexion (0) & $54.7 \pm 14.4$ & $65 \pm 12.1$ & $\mathrm{NS}$ \\
Extension (0) & $62.4 \pm 13.9$ & $61.8 \pm 13.3$ & $\mathrm{NS}$ \\
Flexion-extension range (0 & $117.1 \pm 24.6$ & $126.8 \pm 22.2$ & $\mathrm{NS}$ \\
Radial inclination (0) & $20.3 \pm 7.8$ & $22.8 \pm 6.8$ & $\mathrm{NS}$ \\
Ulnar inclination (0) & $39.4 \pm 12.1$ & $40.6 \pm 9.5$ & $\mathrm{NS}$ \\
Inclination range (0) & $59.1 \pm 14.1$ & $62.6 \pm 10.3$ & \\
\hline
\end{tabular}

Table (4) Results of Multiple Regression Analysis.

\begin{tabular}{lll}
\hline Independent Variable & Coefficient & p Value \\
\hline Patient age & -0.047 & $\mathrm{NS}$ \\
Affected side & 0.136 & $\mathrm{NS}$ \\
Workers' compensation & -0.432 & 0.036 \\
Pain & -0.046 & $\mathrm{NS}$ \\
$\begin{array}{l}\text { Symptom duration } \\
\text { Preoperative range of motion of the }\end{array}$ & 0.421 & 0.043 \\
wrist & & \\
$\begin{array}{l}\text { Preoperative grip strength (percentage } \\
\text { of unaffected side) }\end{array}$ & 0.345 & $\mathrm{NS}$ \\
$\begin{array}{l}\text { Preoperative clinical score } \\
\text { Palmer's arthroscopic classification of }\end{array}$ & 0.317 & $\mathrm{NS}$ \\
triangular fibrocartilage complex & 0.425 & $\mathrm{NS}$ \\
lesions & & \\
Ulnar shortening amount & & \\
\hline
\end{tabular}

Table (5) Preoperative and Postoperative Clinical Outcomes

\begin{tabular}{lll}
\hline Criteria & Preoperative & Postoperative \\
\hline Pain score & $6.8 \pm 5.2$ & $22.0 \pm 4.6^{*}$ \\
$\begin{array}{l}\text { Range of wrist motion } \\
\text { (flexion-extension arc) }\end{array}$ & $144.6^{\circ} \pm 28.8^{\circ}$ & $155.8^{\circ} \pm 25.1^{\dagger \dagger}$ \\
Range of forearm motion & & \\
(pronation-supination arc) & $164.8^{\circ} \pm 14.7^{\circ}$ & \\
Grip strength (percentage of unaffected & $165.5^{\circ} \pm 11.3^{\circ}$ & \\
side) & $83.5 \% \pm 27.2 \%$ & \\
Functional status score & $91.1 \% \pm 26.1 \%$ & $20.2 \pm 6.6^{*}$ \\
Overall clinical score & $10.2 \pm 7.1$ & $84.5 \pm 16.4^{*}$ \\
\hline
\end{tabular}

Table( 6) Outcome According to Wrist Grading System of Chun and Palmer.

\begin{tabular}{llllll}
\hline & \multicolumn{2}{l}{ Preoperative* } & \multicolumn{2}{l}{ Postoperative* $^{*}$ P Value } \\
\hline Wrist score & 69.5 & \pm 7.6 & 92.5 & \pm 8.0 & $<0.0001$ \\
Subjective pain score & 9.3 & \pm 3.8 & 17.6 & \pm 3.1 & $<0.0001$ \\
Subjective motion score & 6.9 & \pm 2.1 & 9.4 & \pm 1.1 & $<0.0001$ \\
Objective motion score & 7.8 & \pm 0.9 & 9.2 & \pm 1.3 & $<0.0001$ \\
Objective strength score & 7.6 & \pm 1.9 & 9.0 & \pm 1.5 & 0.0008 \\
\hline
\end{tabular}

Over late a considerable length of time we performed an arthroscopic resection of the distal ulmus thomasii for comparable outcomes. This article will rundown those effects of a review case-control arrangement. The information from claiming these surveys need been accounted for for past papers [11]. Precise survey of the result measures to surgical intercessions to UIS uncovers An blend from claiming nconsistent systems. This deliberate survey synthesizes 36 investigations that report card looking into conclusions of UIS surgery, assesses their quality, and examines the present state of the confirmation behind ulno-carpal decompressive surgeries. 


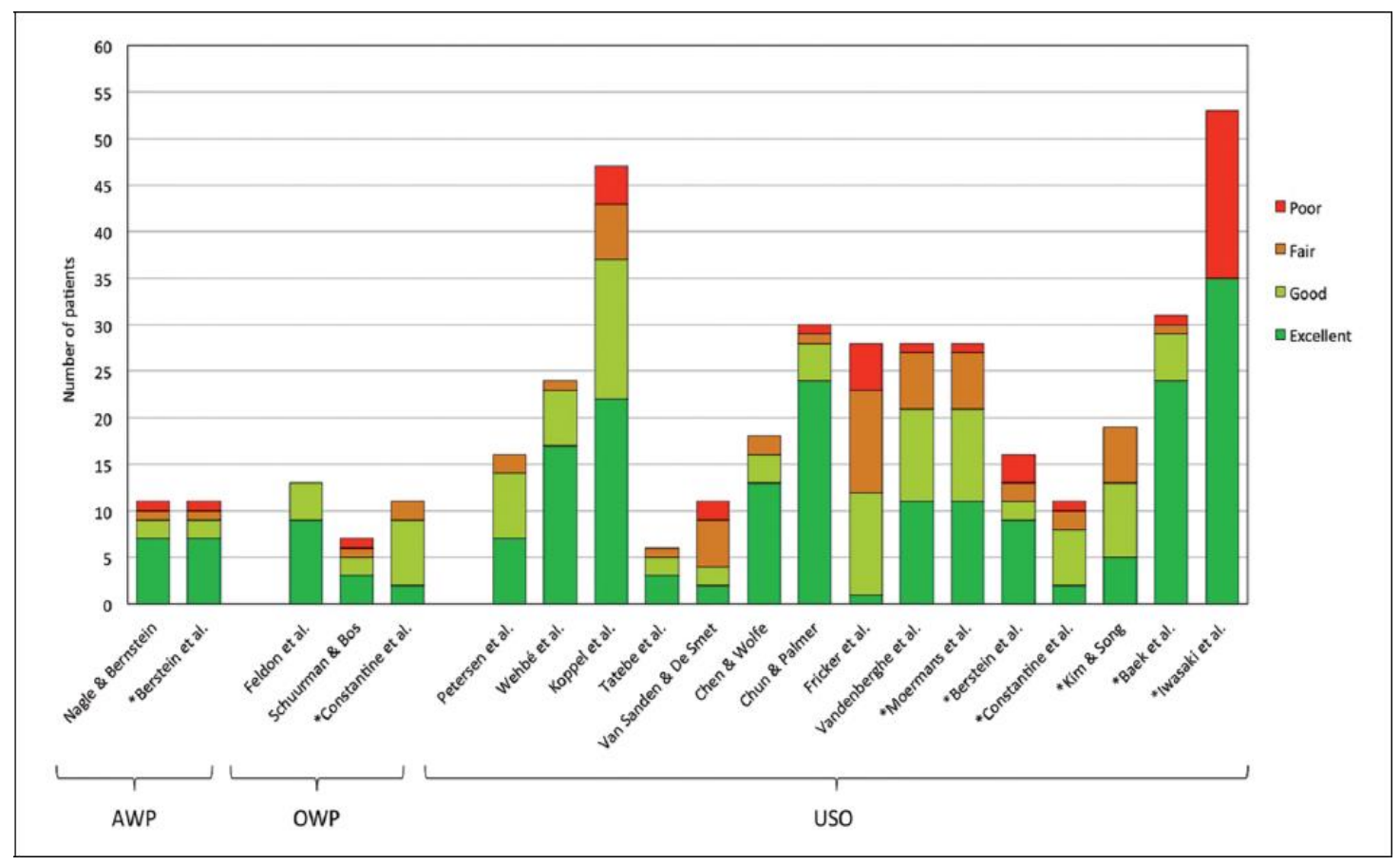

Fig (1) Subjective patient ratings. Asterisk (*) denotes high quality study. Note that Iwasaki et al. (2007) grouped out-comes into 'excellent or good' and 'fair or poor'. For the subjective rating tool used in each study, see Appendix D (available online).

Components connected with UIS include: [1] intrinsic sure UV; [2] spiral shortening Concerning illustration an aftereffect about malunited distal spiral fracture, spiral mind excision, alternately premature distal spiral physeal closure; Also [3] changing sure uv coming about because of wrist pronation What's more Commanding grip. A portion investigations accounted only around whichever post-traumatic UIS alternately idiopathic infection UIS, Furthermore a number didn't define. Future investigations ought to incorporate aetiologic factors so Likewise will tolerance similar examination.

The Detsky score need been used in orthopedic writing Similarly as a system for personal satisfaction appraisal to randomized trials [12] and need demonstrated dependability [13]. Those score might have been fundamentally altered should tolerance assessment for easier level confirmation for example, such that the event arrangement What's more associate investigations [14]. Investigations that provided for level iv proof went clinched alongside caliber from 1-8 crazy for 10, and investigations that provided for level iii confirmation went On personal satisfaction starting with 5-7 crazy about 10 .

Exact reporting weight for pre- Furthermore postoperative ulna variances may be from claiming way vitality. Agreement "around writers might have been should attain a post-operative uv of 0 to $-1 \mathrm{~mm}$. Those larger part for investigations measured uv with those wrist On impartial revolution utilizing those system for perpendiculars [15] measured uv for those wrist done unbiased revolution utilizing the system for concentric circles [16] measured uv for the pronated grip see. Ten investigations didn't point out which technique might have been used to figure out pre- Also post-operative uv. Lower arm rota-tion need noteworthy sway on the position of the span relative of the ulna, with critical implica-tions for measuring uv radiographically (Quigley et al. , 2013). Novel strategies that detract the changing way from claiming uv under consideration, for example, such that four-phase grip attractive reverberation imaging, might a chance to be advantageous [17].

[18] principal accounted the AWP tech-nique. Favorable circumstances incorporate lesquerella surgical pain, lesquerella dis-ruption of dorsal radiocarpal Furthermore radioulnar capsules, What's more no prerequisite to equipment evacuation or hard Uni [19]. Hindrances incorporate the truth that lesquerella ulmus thomasii could make resected compared with exchange methods. [19] proposed that An sure uv $>4 \mathrm{~mm}$ is An contra-indication should AWP. Clinched alongside addition, sure writers [19] treated an soundness TFCC Likewise a con-tra-indication with performing AWP to UIS. The fundamental muddling starting with AWP is amendment will open surgery [18].

The routines about assessing those results from claiming surgi-cal intercession for UIS were An heterogeneous blend from claiming subjective What's more targets measures. Destination out-comes measures accounted by investigations included pre-and postoperative ulna variance, reach for motion, grip strength, Furthermore chance on Uni. Since a standout amongst 
those trademark indications of UIS is ache for Commanding grip, we recommended that pre- and postoperative grip strength, communicated Likewise a rate of the non-injured wrist, will be An of service result measure to incorporate On future investigations. Subjective results were news person for much a greater amount regularity, however for those same absence of Institutionalization. Few of the results measures utilized bring turned out legitimacy and dependability. For this reason, we propose that future Scrutinize utilize validated scoring frameworks.

Those writers distinguish a few constraints on this Audit. Included investigations might a chance to be subject should Choice segregation racial inclination provided for that both the AWP and OWP are restricted in the amount for ulmus thomasii that camwood a chance to be regarded. The altered Detsky scoring framework might have been used with give a portion measure about personal satisfaction of the analysis, and the designa-tion from claiming $\geq 6 / 10$ continuously 'high quality' might have been discretionary. The heterogeneity for systems utilized in the UIS writing repressed measurable Investigation. Those etiology of UIS in the investigations being reviewed might have been not considered, What's more On a number cases might have been not news person. Over addition, the tech-niques What's more gadgets used to accomplish USO differed sub-stantially. These possibility confounders Furthermore their obscure impacts might profit starting with future research.

\section{Conclusion}

Accessible proof indicates that arthroscopic wafer methodology What's more open wafer system might a chance to be feasible plan B of the a greater amount well known ulmus thomasii shortening osteotomy, Yet clinical prevalence is yet to a chance to be made. Future Scrutinize ought further bolstering concentrate on prospective companion routines What's more ought to report card member results utilizing approved scoring routines.

\section{References}

[1] GD. Chloros, ER. Wiesler, GG.Poehling, Current concepts in wristarthroscopy. Arthroscopy, Vol. 24, PP.343-354, 2008.

[2] K. D. Bickel, Arthroscopic treatment of ulnar impaction syndrome. The Journal of hand surgery, Vol. 33, PP.1420-1423, 2008.

[3] K. Sachar, Ulnar-sided wrist pain: evaluation and treat-ment of triangular fibrocartilage complex tears, ulno-carpal impaction syndrome, and lunotriquetral ligament tears. J Hand Surg Am, Vol. 33, PP.1669-79, 2008.

[4] SC. Tay, K. Tomita, RA. Berger, The "ulnar fovea sign" for defining ulnar wrist pain: an analysis of sensitivity and specificity. J Hand Surg, Vol. 32A, PP.438-444, 2007.

[5] A. Watanabe, F. Souza, PS. Vezeridis, Ulnar-sided wrist pain II: Clinical imaging and treat-ment. Skeletal Radiol, Vol. 39, PP.837-57, 2010.
[6] KL. Markolf, SG. Tejwani, P. Benhaim, Effects of wafer resection and hemiresection from the distal ulna on load-sharing at the wrist: a cadaveric study. J Hand Surg Am, Vol. 30, PP.351-8, 2005.

[7] GH. Baek, MS. Chung, YH. Lee, HS. Gong, Ulnar shortening osteotomy in idiopathic ulnar impaction syndrome. J Bone Joint Surg Am, Vol. 87, PP.2649-2654, 2005.

[8] G. Feldkamp, The arthroscopic "wafer procedure" in degenerative disc ulnocarpal tears with ulnocarpal compression syndrome. Techniques, indications, results [in German]. Orthopade, Vol. 33, PP.685-691, 2004.

[9] MA. Bernstein, DJ. Nagle, A. Martinez, JM Jr. Stogin, TA. Wiedrich, A comparison of combined arthroscopic triangular fibrocartilage complex debridement and arthroscopic wafer distal ulna resection versus arthroscopic trian-gular fibrocartilage complex debridement and ulnar shortening osteotomy for ulnocarpal abutment syndrome. Arthroscopy, Vol. 20, PP.392-401, 2004.

[10] A. Moermans, I. Degreef, L. De Smet, Ulnar shortening osteotomy for ulnar ideopathic impaction syndrome. Scand J Plast Reconstr Surg Hand Surg, Vol. 41, PP.310-314, 2007.

[11] L. Vandenberghe, I. Degreef, Ulnar shortening or arthroscopic wafer resection for ulnar impaction syndrome. Acta Orthop Belg, Vol. 78, PP.323-326, 2012.

[12] AS. Detsky, CD. Naylor, K. O'Rourke, AJ. McGeer, KA. L'Abbe, Incorporating variations in the quality of individual rand-omized trials into meta-analysis. J Clin Epidemiol, Vol. 45, PP.255$65,1992$.

[13] M. Bhandari, RR. Richards, S. Sprague, EH. Schemitsch, The quality of reporting of randomized trials in the Journal of Bone and Joint Surgery from 1988 through 2000. J Bone Joint Surg Am, Vol. 84-A, PP.388-96, 2002.

[14] SA. Macadam, M. Bezuhly, KA. Lefaivre, () . Outcomes measures used to assess results after surgery for cubital tunnel syndrome: a systematic review of the literature. J Hand Surg Am, Vol. 34, PP.1482-91, 2009.

[15] AH. Schuurman, KE. Bos, he ulno-carpal abutment syn-drome. Follow-up of the wafer procedure. J Hand Surg Br, Vol. 20, PP.171-7, 1995.

[16] MM. Tomaino, M. Shah, Treatment of ulnar impaction syn-drome with the wafer procedure. Am J Orthop, Vol. 30, PP.129-33, 2001.

[17] T. Oda, T. Wada, K. Iba, M. Aoki, Reconstructed animation from four-phase grip MRI of the wrist with ulnar-sided pain. J Hand Surg Eur, Vol. 38, PP.746-50, 2013.

[8] GA. Buterbaugh, Ulnar impaction syndrome: Treatment by arthroscopic removal of the distal ulna. Tech in Orthop, Vol. 7, PP.66-71, 1992. 
[19] DJ. Nagle, MA. Bernstein, Laser-assisted

18, PP.1046-1051, 2002. arthroscopic ulnar short-ening. Arthroscopy, Vol. 